Doi: 10.22478/ufpb.1983-1579.2018v3n11.33777 http://periodicos.ufpb.br/ojs2/index.php

\title{
REUNI E FLEXIBILIZAÇÃo CURRICULAR: o caso do curso de Pedagogia da UFAL- Campus Arapiraca
}

REUNI Y FLEXIBILIZACIÓN CURRICULAR: el caso del curso de pedagogía de la UFAL-Campus Arapiraca

Lavoisier Almeida Santos

\begin{abstract}
Resumo: O presente artigo é uma reflexão sobre a experiência formativa da primeira turma do curso de Pedagogia da Universidade Federal de Alagoas (UFAL) - Campus Arapiraca. O referido curso apresenta uma estrutura curricular flexibilizada em Troncos de Conhecimento, obedecendo ao princípio economicista do Programa de Expansão e Reestruturação das Universidades Federais (REUNI) de expandir a educação superior pública por meio do melhor aproveitamento das estruturas física e humana das universidades federais, oferecendo, aos seus graduandos, um itinerário formativo diferenciado. Objetiva-se, pois, analisar o processo de implementação da flexibilização curricular no curso de Pedagogia da UFAL-Campus Arapiraca e refletir, por meio da análise de conteúdo, como gestores, professores e alunos da primeira turma do referido curso se apropriaram, em suas respectivas práticas, desse formato curricular flexibilizado.
\end{abstract}

Palavras-chave: REUNI. Flexibilização Curricular. Curso de Pedagogia.
Resumen: El presente articulo es una reflexión sobre la experiencia formativa de la primera clase del curso de Pedagogía de la Universidad Federal de Alagoas (UFAL) - Campus Arapiraca. El referido curso presenta una estructura curricular flexibilizada en Troncos de Conocimiento, obedeciendo al principio economicista del Programa de Expansión y Reestructuración de las Universidades Federales (REUNI) de expandir la educación superior publica por medio del mejor aprovechamiento de las estructuras físicas y humanas de las universidades federales, ofreciendo a sus graduados, un itinerario formativo diferenciado. Su objetivo es analizar el proceso de implementación de la flexibilización curricular en el curso de pedagogía de la UFAL-Campus Arapiraca y reflejar, por medio del análisis del contenido, como gestores, maestros y alumnos de la primera clase del curso de Pedagogía se apropiaran, en sus respectivas practicas, de ese formato curricular flexibilizado.

Palabras Clave: REUNI. Flexibilización Curricular. Curso de Pedagogía.

\section{O REUNI E A REESTRUTURAÇÃO CURRICULAR DAS UNIVERSIDADES BRASILEIRAS}

O presente artigo objetiva refletir sobre a experiência formativa da primeira turma do curso de Pedagogia da Universidade Federal de Alagoas no Campus Arapiraca. Localizado no agreste alagoano, esse Campus corresponde à primeira etapa do Projeto de Interiorização da UFAL e foi criado a partir da idéia de reestruturação acadêmico-curricular proposta pelo Programa de Reestruturação e Expansão das Universidades Federais (REUNI) às Instituições de Ensino Superior (IES) federais em seus variados processos de expansão e interiorização:

Art. $1^{\circ}$ Fica instituído o Programa de Apoio a Planos de Reestruturação e Expansão das Universidades Federais - REUNI, com o objetivo de criar condições para a ampliação do acesso e permanência na educação superior, no nível de graduação, pelo melhor aproveitamento da estrutura física e de recursos humanos existentes nas universidades federais (BRASIL, 2007a, Art $1^{\circ}$, grifo nosso).

A expressão Melhor aproveitamento da estrutura física e de recursos humanos, presente no artigo primeiro do decreto REUNI (BRASIL, 2007a) e explicada no glossário de suas Diretrizes Gerais como "Otimização dos recursos existentes nas universidades federais" (BRASIL, 2007b, p.24), traz implícito o pensamento de que as universidades, seus técnicos, docentes e seus espaços estão ociosos e é possível aumentar a oferta nos diversos cursos sem mudanças significativas em suas estruturas.

\footnotetext{
${ }^{1}$ Professor de Língua Portuguesa da rede estadual de Sergipe e de Alagoas, mestre em educação (PPGE-UFAL) e doutorando em letras (PPGLL-UFAL). E-mail: <lavoisierdealmeida@hotmail.com>
} 
Sendo assim, o substantivo "otimização = melhor aproveitamento" é a epifania da lógica economicista do capital que deve reger as relações e os direcionamentos das universidades brasileiras. Otimizar as universidades significa dizer que a

[...] estrutura física e os recursos humanos existentes são suficientes, apenas não estão sendo bem aproveitados. Isso equivale a afirmar que as universidades públicas possuem estrutura física e recursos humanos ociosos. Donde se infere que melhor aproveitamento da estrutura física é aumento de alunos em sala de aula; otimização de recursos humanos é sobrecarga do trabalho do professor e aumento de horas-aula, aumento de alunos por turma, aumento quantitativo da produção acadêmica (CAVALCANTE; SILVA SOBRINHO, 2012, p. 103).

A partir da lógica da otimização presente no REUNI, há uma crescente intensificação e precarização do trabalho docente com um forte movimento de sucateamento das universidades públicas (SGUISSARDI, 2008; SILVA JUNIOR; SGUISSARDI, 2013). As únicas exigências para que qualquer universidade federal pudesse participar do REUNI era o de a universidade preparar um projeto, conhecido como Projeto REUNI, voltado à expansão e reestruturação, e utilizar a verba advinda do programa tão somente com seu processo de expansão e/ou interiorização com reestruturação curricular dos cursos expandidos e/ou interiorizados, trazendo drásticas consequências à sistematização das universidades em seu tripé de ensino, pesquisa e extensão, à formação docente e, por consequência, à educação básica e à comunidade em seus diversos setores e seguimentos.

O Projeto REUNI de cada universidade deveria seguir, pois, as diretrizes da política do governo Lula da Silva para a educação superior pública baseada na redução das taxas de evasão, ampliação da mobilidade estudantil, diversificação das modalidades de educação, revisão da estrutura acadêmica e otimização das universidades federais (BRASIL, 2007a; 2007b). Tais elementos já estavam postos aos países periféricos, desde 1995, no documento do Banco Mundial: Ensenãnza superior: las lecciones derivadas de la experiência. Nesse, são analisadas, dentre outras coisas em relação à educação superior, as principais dimensões da crise pela qual passa esse nível de ensino nos países em desenvolvimento e os elementos a serem considerados na reforma da educação superior a fim de superar a referida crise:

[...] baixa relação professor/aluno, necessidade de ampliação do acesso de grupos sociais tradicionalmente menos privilegiados à educação superior, combate às elevadas taxas de evasão e repetência, redução de gastos públicos por estudantes, necessidade de melhorar a qualidade de investigação universitária, adoção de programas de educação à distância como estratégia para aumentar o acesso de grupos menos favorecidos a baixo custo (ARRUDA, 2011, p. 97).

Essas diretrizes apontam para uma particularidade do REUNI que é a da expansão com revisão da estrutura acadêmica por meio da otimização de recursos. No caso da UFAL, o Campus Arapiraca, primeira atividade de seu processo expansão e interiorização com reestruturação curricular, surge exatamente desse contexto de otimização de recursos e, como consequência, todos os cursos, ofertados naquele Campus, deveriam ter um modelo curricular econômico em recursos humanos e físicos:

Os cursos de graduação oferecidos no Campus Arapiraca, distintos daqueles do Campus Maceió, adotam projetos pedagógicos inovadores, racionais e flexíveis, e novos padrões e procedimentos institucionais, consoantes com as novas dinâmicas do conhecimento e com os objetivos da formação competente e cidadã, mas sem sacrificar a qualidade nem deixar de ser apropriado às novas condições de operação da Instituição (UFAL, 2008, p. 18, grifo nosso).

Segundo o Projeto REUNI da UFAL, os cursos oferecidos no interior do estado de Alagoas deveriam ter uma estrutura curricular inovadora e econômica que seria marcada pela flexibilização curricular. A inovação curricular se deu pela organização dos cursos de graduação em Troncos de Conhecimento. $O$ Tronco Inicial é caracterizado como "parte integrante, obrigatória e comum do projeto pedagógico de todos os cursos de graduação interiorizados pertencentes a cada Eixo Temático" (UFAL, 2005, p. 48). Sendo assim, todos os cursos oferecidos pela UFAL, no Campus Arapiraca, têm o Tronco Inicial como 
primeira etapa formativa de seus ingressos. Esse tronco tem a duração de um semestre, ofertando 400 horas divididas entre quatro disciplinas (UFAL, 2005, p. 49).

O Tronco Intermediário, de conteúdo comum aos cursos de cada Eixo Temático, reúne os cursos de graduação de cada eixo de conhecimento com o objetivo de contribuir, a partir da oferta de disciplinas instrumentais de síntese e por um projeto integrador, com a discussão crítica dos saberes inerentes à formação básica comum a esses cursos (UFAL, 2005). Esse Tronco tem também a duração de um semestre e suas disciplinas variam a depender do eixo temático no qual os cursos se encontrem. Por fim, o Tronco Profissionalizante apresenta os conteúdos e discussões próprios a cada curso, observando as características e idiossincrasias do Projeto Pedagógico de cada um, tendo duração variável por conta da especificidade de cada formação profissional, como sistematizado no quadro abaixo:

\section{Quadro 1: Modelo curricular - Campus Arapiraca}

\begin{tabular}{|c|c|c|c|c|}
\hline $\begin{array}{c}\text { EIXOS } \\
\text { TEMÁTICOS }\end{array}$ & CURSOS & TRONCO INICIAL & TRONCO INTERMEDIÁRIO & $\begin{array}{c}\text { TRONCO } \\
\text { PROFISSIONA- } \\
\text { LIZANTE }\end{array}$ \\
\hline $\begin{array}{l}\text { Eixo das } \\
\text { Agrárias }\end{array}$ & $\begin{array}{l}\text { Agronomia; } \\
\text { Zootecnia; } \\
\text { Medicina } \\
\text { Veterinária; }\end{array}$ & \multirow{6}{*}{$\begin{array}{l}\text { Disciplinas comuns a } \\
\text { todos os cursos dos } \\
\text { diversos eixos: } \\
\text { “Sociedade, natureza } \\
\text { e desenvolvimento: } \\
\text { relações locais e } \\
\text { globais” (120 h); } \\
\text { “Produção do } \\
\text { conhecimento: ciência } \\
\text { e não-ciência” (120 h); }\end{array}$} & $\begin{array}{c}\text { Seminário Integrador II; } \\
\text { Química Geral; Matemática e } \\
\text { Estatística; Ecologia; Biologia } \\
\text { geral. } \\
\end{array}$ & $\begin{array}{l}\text { Disciplinas } \\
\text { específicas de } \\
\text { cada curso. }\end{array}$ \\
\hline $\begin{array}{c}\text { Eixo da } \\
\text { Educação }\end{array}$ & $\begin{array}{c}\text { Matemática; } \\
\text { Física; Biologia; } \\
\text { Química; } \\
\text { Educação Física. }\end{array}$ & & $\begin{array}{l}\text { Seminário Integrador II; } \\
\text { Química Geral; Profissão } \\
\text { Docente; Fundamentos de } \\
\text { Matemática I; Física Geral; } \\
\text { Biologia geral. }\end{array}$ & $\begin{array}{c}\text { Disciplinas } \\
\text { específicas de } \\
\text { cada curso. }\end{array}$ \\
\hline $\begin{array}{l}\text { Eixo de } \\
\text { Gestão }\end{array}$ & $\begin{array}{l}\text { Administração; } \\
\text { Ciências da } \\
\text { Computação; } \\
\text { Turismo. }\end{array}$ & & $\begin{array}{c}\text { Introdução à Tecnologia da } \\
\text { Informação; Introdução a } \\
\text { Sistemas de Informação; } \\
\text { Noções de matemática e } \\
\text { estatística; Introdução à } \\
\text { Administração; Seminário } \\
\text { Integrador } 2 \\
\end{array}$ & $\begin{array}{l}\text { Disciplinas } \\
\text { específicas de } \\
\text { cada curso. }\end{array}$ \\
\hline $\begin{array}{c}\text { Eixo das } \\
\text { Humanidades }\end{array}$ & $\begin{array}{l}\text { Serviço Social; } \\
\text { Psicologia. }\end{array}$ & & $\begin{array}{l}\text { Trabalho e Sociabilidade; } \\
\text { Pesquisa em Ciências Sociais; } \\
\text { Introdução à Psicologia; } \\
\text { Introdução à Filosofia; } \\
\text { Seminário integrador II. }\end{array}$ & $\begin{array}{l}\text { Disciplinas } \\
\text { específicas de } \\
\text { cada curso. }\end{array}$ \\
\hline Eixo da Saúde & Enfermagem. & & $\begin{array}{l}\text { Seminário Integrador II; } \\
\text { Saúde e Sociedade; } \\
\text { Parasitologia; Biologia } \\
\text { Celular e Molecular; } \\
\text { Anatomia e histologia. }\end{array}$ & $\begin{array}{l}\text { Disciplinas } \\
\text { específicas de } \\
\text { cada curso. }\end{array}$ \\
\hline $\begin{array}{c}\text { Eixo da } \\
\text { Tecnologia }\end{array}$ & $\begin{array}{l}\text { Arquitetura; } \\
\text { Engenharia da } \\
\text { Pesca. }\end{array}$ & & $\begin{array}{l}\text { Seminário Integrador II; } \\
\text { Geometria Descritiva; } \\
\text { Geometria Analítica; } \\
\text { Fundamentos de Cálculo; } \\
\text { Desenho Técnico; Desenho } \\
\text { Auxiliado por Computador; }\end{array}$ & $\begin{array}{c}\text { Disciplina } \\
\text { específicas de } \\
\text { cada curso. }\end{array}$ \\
\hline
\end{tabular}

Fonte: $\mathrm{O}$ autor.

No que diz respeito ao modelo universitário adotado para o processo de interiorização da UFAL, o forte argumento presente no Projeto de interiorização da UFAL (2005) e no Plano REUNI da UFAL (2007) é de que esse modelo de universidade responderia às vocações econômicas do agreste e do sertão alagoanos. Todavia, o modelo proposto para a chegada da UFAL ao interior de Alagoas foi o mesmo utilizado no processo de expansão de outras universidades do Brasil, afinado com o processo de Bolonha 
e com o projeto Universidade Nova, como indicam alguns estudos (ARAUJO, 2011; FONSECA, 2013; PAULA, 2009; SANTOS, 2016; WESKA, 2012).

\section{O CAMPUS ARAPIRACA E A FLEXIBILIZAÇÃO CURRICULAR: o caso do curso de pedagogia}

O objetivo desta seção é analisar como o projeto acadêmico-administrativo inovador, racional, flexível e econômico em recursos humanos e materiais, pensado para os Campi interiorizados da UFAL, é materializado no curso de Pedagogia do Campus Arapiraca. Para tanto, realizamos entrevistas e aplicamos questionários com gestores, professores e alunos ligados à primeira turma do referido curso, totalizando uma população de 49 (quarenta e nove) sujeitos.

Os dados levantados foram analisados através da técnica de análise de conteúdo, a qual tem como objetivo "[...] assinalar e classificar de maneira exaustiva e objetiva todas as unidades de sentido existentes no texto. [...] [e] fornecer indicadores úteis aos objetivos da pesquisa" (OLIVEIRA, et al., 2003, p. 6, grifos do autor). Nesse sentido, a análise dos dados buscou responder às inquietações suscitadas pela problemática da pesquisa e aos objetivos que delinearam o trajeto da mesma. Entendemos, a partir de Bardin (2009), que a análise de conteúdo é

[...] um conjunto de técnicas de análise das comunicações. Não se trata de um instrumento, mas de um leque de apetrechos; ou com maior rigor, será um único instrumento, mas marcado por uma grande disparidade de formas e adaptável a um campo de aplicação muito vasto: as comunicações (BARDIN, 2009, p. 33, grifos da autora).

Os dados obtidos por meio da aplicação de questionário e da realização de entrevistas com professores, alunos e gestores, foram sistematizados através de grelhas de análise para facilitar a compreensão e a análise das unidades de sentido que serviram de indicadores para alcançarmos algumas respostas a questionamentos suscitados pela problemática da presente pesquisa, bem como para a construção das categorias analíticas finais.

A análise das entrevistas foi orientada pelas seguintes perguntas: "[...] O que essa pessoa está a dizer realmente? Como é isso dito? [...]. O que não diz ela? O que diz sem o dizer? Como é que as palavras, as frases e as sequências se encadeiam entre si? Qual é a lógica discursiva do conjunto? [...]" (BARDIN, 2009, p. 94), pois entendemos que "[...] é preciso articular a superfície dos textos, descritas e analisadas, pelo menos em alguns elementos característicos e os fatores que determinaram estas características, deduzidas logicamente (OLIVEIRA, et al., 2003, p. 4).

Tendo em vista que "o objetivo final da análise de conteúdo é fornecer indicadores úteis aos objetivos da pesquisa" (OLIVEIRA, et al., 2003, p. 6), elegemos, ancorados na categoria de análise da contradição, as categorias analíticas iniciais "flexibilização curricular, perspectivas em relação ao curso de Pedagogia e condições de estudo e trabalho" que serviram de base para elaboração das entrevistas e dos questionários.

Da análise do material colhido por meio das entrevistas e questionários e sistematizado em grelhas de análise, emergiram as categorias analíticas finais desta pesquisa: identidade, precarização e impacto social. Identidade e precarização têm origem exatamente no centro da temática de nosso objeto de estudo: a flexibilização curricular. A categoria impacto social, por sua vez, surge atrelada à nossa perspectiva analítica da contradição, pois, mesmo em meio aos problemas de identidade docente/discente e o contexto de precariedades ocasionado pelo modelo de universidade interiorizado, o conteúdo das entrevistas apresenta elementos para identificar algumas mudanças sociais positivas no agreste alagoano com a chegada da UFAL ao interior.

Nesse sentido, as categorias analíticas finais, elementos de conteúdo agrupados por afinidade temática, foram definidas por meio de um modelo misto no qual "as categorias são selecionadas no início, mas o pesquisador se permite modificá-las em função do que a análise aportará" (SILVA, 2005, p. 76).

Os questionários foram respondidos por 31 (trinta e um) alunos de um total de 36 (trinta e seis) e 14 (quatorze) professores do curso de Pedagogia, de um total de 21 (vinte e um), sendo que, no período de realização da pesquisa de campo, estavam em atividades apenas 14 (quatorze) professores, pois 5 
(cinco) estavam afastados para qualificação (doutorado e pós-doc), 1 (um) de licença maternidade e 1 (um) afastado por problemas de saúde.

Entre os entrevistados estão 4 (quatro) alunos, 2 (dois) professores, 2 (dois) gestores. Os alunos que foram entrevistados participaram da pesquisa também como respondentes de questionários. Os outros entrevistados não responderam a questionários, participando da pesquisa tão somente por meio da entrevista.

O critério de inclusão dos respondentes dos questionários - alunos e professores - foi a vinculação ao curso de Pedagogia, com atividades desenvolvidas em qualquer um dos troncos de conhecimento (inicial, intermediário, profissionalizante), em qualquer época, desde a criação do curso em 2011. No caso das entrevistas realizadas com gestores, professores, e alunos, o critério de inclusão dos sujeitos foi o de ter participado da discussão em âmbito nacional ou local do Programa REUNI e/ou do processo de interiorização da UFAL e/ou da criação/atuação do Curso de Pedagogia do Campus Arapiraca.

Para preservar a identidade desses Participantes, como estabelecido no Termo de Consentimento Livre e Esclarecido (T.C.L.E), em seu tópico de $n^{\circ} 5$, que garante o sigilo da identidade dos mesmos, preservando-os de danos físicos e/ou morais ou qualquer tipo de constrangimento, caracterizamos os sujeitos participantes da pesquisa com as seguintes nomenclaturas: Gestor 1, Gestor 2, Professor 1, Professor 2, seguindo a sequência até Professor 16 e Aluno 1, Aluno 2, seguindo a sequência até Aluno 31.

\section{O CURSO DE PEDAGOGIA DA UFAL: Campus Arapiraca: uma questão de Identidade}

Para entender melhor o surgimento e o funcionamento do curso de Pedagogia no Campus Arapiraca, procedemos com uma análise de documentos da UFAL e do MEC referentes ao curso de pedagogia do Campus Arapiraca, a saber: Projeto Político Pedagógico (UFAL, 2010; 2014) e o Plano de Desenvolvimento Institucional 2013-2017 (UFAL, 2013), bem como de entrevistas e questionários que registraram a experiência e percepções de gestores, de professores e de alunos envolvidos com o curso de Pedagogia do referido Campus.

Segundo seu projeto político-pedagógico (PPP) (UFAL, 2010), o curso de Pedagogia surge para atender a duas demandas intensas da região agrestina: a primeira caracterizada pela carência de professores para atuar no ensino fundamental e na educação infantil; a segunda caracterizada pela existência de profissionais não qualificados que já se encontravam inseridos no mercado de trabalho, atuando, sem formação apropriada, na educação básica. Nesse sentido, o PPP do curso de pedagogia Campus Arapiraca parte de dois pressupostos precisos para justificar a oferta noturna do curso de pedagogia:

O primeiro está relacionado à ampliação do acesso à educação superior pela via pública [...]. A constatação da não oferta de curso superior de Pedagogia no turno noturno pela via pública em Arapiraca, ocorre quando se averigua que a demanda existente na Região para o referido curso, somente tem oportunidade de acesso em uma instituição pública (UNEAL) no turno diurno, cabendo à rede privada de ensino superior o atendimento à demanda, que supomos, somente ter possibilidade de acesso ao ensino superior no turno noturno. $O$ segundo pressuposto está relacionado à função social que deve exercer a Universidade Federal de Alagoas na região do Agreste Alagoano, uma vez que ainda existe carência de profissionais habilitados em nível superior para atuar na Educação Infantil, anos iniciais do Ensino Fundamental (UFAL, 2010, p. 15-16).

Entende-se, a partir do PPP de Pedagogia, que esse curso surge para alcançar dois objetivos bem definidos e entrelaçados: um ligado à consolidação da oferta de educação superior pública e gratuita para melhoria da qualidade da educação básica por meio da formação; outro ligado à preocupação de que essa oferta contemple a classe trabalhadora que se ocupa diurnamente para garantir a própria subsistência, restando apenas o último turno para poder lutar por melhores condições de existência por meio do estudo. 
Contudo, ao entrevistar professores que estiveram à frente do processo de criação e da gestão do curso de Pedagogia, o primeiro dado comum que aparece, no bojo dessas entrevistas, é a informação de que o curso de Pedagogia surge, em primeira instância, da necessidade dos professores que trabalhavam inicialmente no Campus Arapiraca com as disciplinas pedagógicas nas licenciaturas, mas sem pertencer a nenhum curso em específico a partir do qual os mesmos pudessem falar e apresentar seus anseios, necessidades e posicionamentos:

Antes de participar da coordenação da Pedagogia, eu fiquei um tempo como coordenadora do que a gente chamava de Núcleo Pedagógico. Porque a gente não tinha Pedagogia, e nós éramos um grupo grande de professores, que dava aula pra várias licenciaturas. Na época, se eu não me engano, eram 5 licenciaturas. $E$ a gente não participava das reuniões quando tinha disponibilidade de vagas: "Ah, universidade tá com vagas, pra onde, onde a gente vai alocar essas vagas?” A gente não tinha participação (...). Então a gente montou esse núcleo, fez uma coordenação que atuava basicamente como uma coordenação de curso. Então, a partir da montagem desse núcleo, a gente começou a ter voz ali. A gente conseguiu professores pra o núcleo. Porque o número de cursos em licenciatura ia aumentando e continuava o mesmo número de professores das disciplinas pedagógicas. Então assim, ia sobrecarregando os professores que estavam ali. (Gestor 2, entrevistado 3).

O surgimento do curso de Pedagogia no Campus Arapiraca está intrinsicamente ligado às necessidades dos professores das disciplinas pedagógicas que atuavam em várias licenciaturas, mas não eram considerados como docentes de nenhuma delas. Esses professores eram uma espécie de outsider, isto é, de professores sem identidade que eram estranhos aos cursos que lecionavam. Nesse sentido, os professores que atuavam inicialmente nas licenciaturas pleitearam a criação de um Núcleo Pedagógico que nem existia na concepção da estrutura acadêmico-administrativa do Campus, mas que serviria de espaço estratégico para solidificação da identidade pedagógica no Eixo da Educação no Campus:

A gente conseguia perceber uma certa desvalorização dos Pedagogos no eixo da Educação, perante ao nosso estudo. Então assim, a nossa briga ali sempre foi muito ferrenha para conseguir o nosso espaço antes de ter o curso de Pedagogia. Aí depois que a gente conseguiu o curso de Pedagogia. Aí durante esse período, que foi em 2010, se conseguiu a implementação do curso no Campus. E, a partir daí, a gente começou a ter mais vez e voz ali (Gestor 2, entrevistado 3).

Mesmo sem fazer parte da estrutura inicial do Campus Arapiraca, o Núcleo Pedagógico, além de servir para fomentar e solidificar uma identidade pedagógica aos professores e às licenciaturas, lançava também os germes para o nascimento do curso de Pedagogia. Esse núcleo foi pensado como um espaço político-estratégico no qual os docentes responsáveis pelas disciplinas pedagógicas começassem a ter visibilidade, apresentando seus posicionamentos e suas demandas.

O problema da identidade docente existente no eixo da educação foi um dado comum apresentado, em entrevista, por todos os sujeitos envolvidos com a criação do curso de Pedagogia, donde se infere que esse era o contexto interno do Campus Arapiraca para a criação do referido curso:

Então havia uma demanda nossa, no sentido de que a gente precisava dessa identificação com algum curso e a gente não tinha, e havia, há, ainda hoje, muitos pedagogos no núcleo que originou o curso de Pedagogia. Então havia uma demanda nossa, havia ao mesmo tempo a necessidade de atender uma demanda que existia na região [...]. A possibilidade de ofertar essa, esse curso, possibilitando que muitas pessoas da classe trabalhadora pudessem fazer o curso de Pedagogia e não se esforçar pra pagar uma mensalidade e ter um curso de qualificação mais reduzida. Então houve, havia uma demanda, havia um interesse nosso, e ao mesmo tempo houve uma brecha aberta pelo MEC e houve também interesse da Pró-reitoria de Graduação na época. Então dadas essas 
condições todinhas, a gente viu a possibilidade de criar o curso de Pedagogia. E junto também foi criada a licenciatura de Letras (Professor 1, entrevistado 4).

Conforme apresentam os documentos e os entrevistados, de fato, havia uma demanda regional para a criação do curso em questão: profissionais que já estavam atuando em escolas, mas ainda não tinham a formação pedagógica necessária para o exercício da docência. Porém, contrariando a pesquisa realizada pela equipe responsável para criação do curso de pedagogia, bem como suas expectativas, o perfil dos alunos matriculados para a primeira turma do curso, mesmo sendo criado noturno, foi outro: “[...] nossas meninas eram todas jovens, recém-saídas do ensino médio e não inseridas no mercado de trabalho [...]" (Gestor 2, entrevistado 3).

Percebe-se, pois, pela problemática apresentada por professores e gestores, que a demanda por um curso de Pedagogia era bem mais interna do Campus de que uma demanda regional. Podemos deduzir que o interesse em criar um curso de Pedagogia, por parte da Pró-Reitoria de Graduação, existia justamente pelo fato de a ausência desse curso gerar uma série de questões entre professores e alunos do Campus Arapiraca, pois, se os professores sentiam-se flutuando, sem ter uma identidade fixa, certamente também os alunos sentiam isso em relação aos seus professores das disciplinas pedagógicas que não eram, na verdade, professor de curso nenhum.

Diante do problema da organização curricular dos cursos de licenciatura do Campus Arapiraca, abundante em disciplinas pedagógicas, era urgente a presença do curso de Pedagogia para melhor orientar os professores dessas disciplinas e repensar o lugar das mesmas nas diversas licenciaturas do Campus:

Há, em Arapiraca, um privilegiamento muito grande na formação desses cursos das disciplinas pedagógicas [...]. A ênfase é cada vez maior na forma do que no conteúdo. É cada vez mais na metodologia do que na substância, do que no fundamento. A gente tem inúmeras disciplinas pedagógicas, tem disciplina sobre gestão, disciplina sobre currículo, sobre avaliação (...) sabe? Variadas disciplinas. Então você preenchia cada vez mais com disciplinas que têm esse caráter mais de pensar metodologia, de pensar gestão, de pensar avaliação, pensar currículo, etc., e esvazia naquilo que é essencial, que é o domínio dos conteúdos de Física e Matemática (Professor 1, entrevistado 4).

Havia, pois, uma fragilidade curricular que era ainda mais agravada pela ausência do curso de Pedagogia para que os professores dessas disciplinas tivessem um apoio, um norte de ação, um espaço para refletir sobre a organização e intencionalidade dessas disciplinas no formato curricular do curso. Esses professores não tinham, na verdade, o mínimo de autonomia dentro do Campus, estando à mercê das licenciaturas de Biologia, Educação Física, Física, Matemática e Química que se encontravam no Eixo da Educação. Essa é, na verdade, a principal razão para a criação do curso.

Contudo, se, por um lado, o surgimento do curso de Pedagogia serviu para amenizar a problemática da identidade docente, fazendo com que esses professores tivessem um curso ao qual eram, de fato, vinculados; por outro, agravou ainda mais a problemática da questão curricular no Campus Arapiraca, pois até 2010, ano de criação dos cursos de Pedagogia e Letras, o Tronco Intermediário do Eixo da Educação ofertava as disciplinas de Seminário Integrador II, Química Geral, Profissão Docente, Fundamentos de Matemática I, Física Geral, Biologia geral como disciplinas comuns às licenciaturas existentes no Campus, conforme apresenta o Quadro 1 exposto na página 90.

Ora, com o surgimento das licenciaturas de Letras e Pedagogia, seria inconcebível um período comum a todas as licenciaturas do Campus com essas disciplinas. Imaginemos os alunos de Letras e Pedagogia, estudando as disciplinas de Fundamentos de Matemática, Física Geral, Química Geral e Biologia Geral com os alunos de Matemática, Física, Química, Biologia e Educação Física. Seria uma realidade acadêmica inviável ou, pelo menos, extremamente tensa.

Frente essa realidade, acontece, em 2010, uma reformulação na organização das disciplinas no Eixo da Educação, transformando o Tronco Intermediário, comum às licenciaturas, em um período 
exclusivamente pedagógico. Nesse Tronco, passa-se a ofertar as disciplinas de Profissão Docente (6oh), Projeto pedagógico, Organização e Gestão do Trabalho Escolar (8oh), Política e Organização da Educação Básica no Brasil (8oh), Desenvolvimento e Aprendizagem (8oh), Libras (6oh) e Seminário Integrador II (40h) (UFAL, 2010).

Percebe-se, pois, que a inovação curricular proposta para Arapiraca não tem por objetivo alcançar a excelência acadêmica exigida pelos novos tempos, mas sim organizar um sistema barato, econômico em recursos humanos e físicos, para operacionalização da educação superior pública. Para preservar a lógica da otimização do Campus Arapiraca, concentra-se, em 2010, várias disciplinas pedagógicas em um único semestre, transformando este período em um lugar comum, podendo ser frequentado no mesmo tempo e no mesmo espaço pelas diversas licenciaturas do Campus, ocasionando novos problemas no que diz respeito à abordagem e à identidade de cada curso.

A mudança das disciplinas que constituíam o Tronco Intermediário do eixo da Educação por causa da criação dos cursos de Pedagogia e de Letras teve, por consequência, uma overdose de disciplinas pedagógicas no primeiro ano de curso das licenciaturas, limitando a formação docente aos Troncos Inicial e Intermediário, tendendo a transformar o Tronco Profissionalizante, o mais extenso do período de formação, em um bacharelado:

A estrutura em Troncos teve por aspecto positivo a viabilidade para o processo de interiorização, entretanto a sua estrutura compromete o processo de identificação e identidade discente junto aos cursos de licenciaturas. A formação docente torna-se periférica quando centralizada no Tronco Intermediário e, no Profissionalizante, nas demais licenciaturas, existe a prioridade nas áreas de formação que se aproximam do bacharelado (Professor 5, questionário 3 ).

No caso específico das licenciaturas ofertadas pela UFAL - Campus Arapiraca, o caráter pedagógico da prática docente torna-se um momento estanque do Tronco Intermediário que, tendo um caráter excessivamente pedagógico, deixa a desejar pela ausência de disciplinas específicas, fazendo com que "os alunos não se sintam no Curso escolhido" (Professor 8, Questionário 6). A esse problema de identidade, soma-se a mentalidade, amplamente aceita por professores e alunos, de que a ausência das disciplinas específicas deve, então, ser superada no Tronco Profissionalizante, dando ao mesmo um caráter predominantemente de bacharelado.

Nesse formato curricular flexibilizado em Troncos de Conhecimento, o aluno passa o primeiro ano do curso sem ter, ao menos, uma disciplina do curso escolhido pelo mesmo no exame de seleção para ingresso na universidade. Tal dado ocasiona sérios problemas aos discentes do Campus, pois "atrasa o contato dos mesmos com as disciplinas específicas do seu Curso [e] concentra disciplinas não tão essenciais para a formação específica em um único semestre" (Professor 15, questionário 13). Segundo o Professor 13, o formato curricular flexível do Campus Arapiraca é favorável à evasão dos alunos, pois o fato dos mesmos só terem acesso às disciplinas específicas no segundo ano do Curso escolhido "[...] gera certa desmotivação e desinteresse pelas disciplinas ofertadas inicialmente" (Professor 13, questionário 11).

Essa falta de interesse é gerada pelo fato de os alunos não se identificarem em seu curso quando chegam à universidade, frustrando o argumento de que essa organização curricular seria uma propedêutica à vida universitária. Ao invés de introduzir e fixar o aluno, saído do ensino médio, na universidade, esse modelo pode desestimular a permanência dos estudantes em tal instituição.

O problema da identidade ocasionado pela organização curricular flexível em Arapiraca é, na verdade, um dado que se repete na fala todos os professores que participaram da pesquisa de campo. Em síntese, podemos dizer que "[...] a estrutura em Troncos impossibilita que os alunos se percebam como integrantes de um Curso, em específico, desde o início da graduação" (Professor 9, questionário 7). Segundo os professores, a questão da identidade é causa de vários outros problemas no Campus como, por exemplo, desestímulo dos alunos, alto índice de evasão, maior tempo para conclusão do curso, pois há um alto índice de reprovação nas disciplinas específicas do Tronco Profissionalizante, dentre outros. 
Também os alunos do curso de Pedagogia percebem problemas em relação à identidade discente, causados pela organização curricular flexibilizada em Troncos de conhecimento, avaliando-a como negativa e prejudicial à formação do pedagogo, pois tal formato "impede o aluno de ter um conhecimento maior de sua área, uma vez que, nesse tempo que passamos no Tronco Inicial e Intermediário, poderíamos ter outras disciplinas específicas, diminuindo o Tronco Profissionalizante" (Aluno 9, questionário 5). Essa questão da extensão temporal do Tronco Profissionalizante é recorrente na fala de quase todos os alunos. Tal dado se justifica pelo fato de o Curso ter inicialmente a previsão de terminar em 2014.2, o que não havia ocorrido até 2016.1, por causa de greves e de uma reformulação curricular do próprio curso.

O Tronco no qual os alunos tiveram mais dificuldades foi o Inicial, como se pode observar nas sequências que seguem:

Penso que o Tronco Inicial é dispensável, pois o percebi como algo que não tinha relação com o meu curso (Aluno 5 , questionário 1).

Tive muitas dificuldades no Tronco Inicial, pois neste período as disciplinas não eram favoráveis, pois as disciplinas não apresentavam significado para o curso que faço (Aluno 8 , questionário 4).

Eu tive grandes dificuldades no Tronco Inicial devido às condições precárias do Campus (Aluno 13, questionário 9).

O Tronco Inicial não favoreceu significativamente à minha formação no aspecto da contextualização. Deveríamos começar estudando os conteúdos de pedagogia (Aluno 16, questionário 12).

O Tronco Inicial não dialogou diretamente com o meu curso. As disciplinas eram boas, mas durante esse semestre não tive contato com meu curso. Coisa que eu queria muito [...] (Aluno 17, questionário 13).

A questão da falta de identidade entre as disciplinas e o curso escolhido durante os Troncos Inicial e Intermediário é recorrente na fala de vários alunos do curso de Pedagogia. É interessante destacar que o Tronco Intermediário é tido como um momento pedagógico das licenciaturas e, mesmo assim, essa crítica é apontada por alunos da Pedagogia, corroborando com o pensamento de alguns professores que percebem que essa estrutura curricular enfatiza a forma em detrimento do conteúdo, destituindo a discussão teórica específica de cada curso durante todo o primeiro ano das licenciaturas.

\section{O CURSO DE PEDAGOGIA DA UFAL-CAMPUS ARAPIRACA: precarização/impacto social}

A primeira turma do Curso de Pedagogia iniciou seus estudos no segundo semestre de $2010 \mathrm{com}$ a proposta de duração de quatro anos, mas, por causa de três greves e do acréscimo de um período a partir do PPC (2014), a referida turma só encerrou o curso no primeiro semestre de 2016.

O primeiro dado que chama a atenção é que, mesmo diante das greves e aumento de um período no decorrer do curso, o índice de evasão da turma, tendo em vista que é um curso noturno, é baixíssimo: dos quarenta alunos matriculados para o curso, apenas quatro desistiram. Dos 36 (trinta e seis) alunos que fazem parte da primeira turma de Pedagogia da UFAL - Campus Arapiraca, 31 (trinta e um) participaram de nossa pesquisa por meio de questionários. Os alunos 1 (um), 2 (dois), 3 (três) e 4 (quatro) foram os únicos alunos que, além de responderem ao questionário, foram também entrevistados.

A mudança de oito para nove períodos, indicada pelo PPC (2014), foi exigida pelo MEC para poder realizar o reconhecimento do curso de Pedagogia e é o primeiro dado que aponta para a precarização do referido curso:

Somos a primeira turma, a sofredora (...). Cursando o nono período que surgiu quando já estávamos no sétimo período. Fomos a "cobaia" e houve despreparo das coordenações de nosso curso. Recentemente algumas pessoas do curso conseguiram passar em concurso público, agora já finalizando e a coordenação 
não soube como agir (...). Apesar de tudo, meu Curso foi um divisor de águas em minha vida e sou grata a todo aprendizado adquirido ao longo dos anos (Aluno 16, questionário 12).

A fala do Aluno 16 revela bem a dicotomia realizada pelo processo de expansão da UFAL que, ao mesmo tempo que é precário e desrespeita o aluno por tal precariedade e desorganização, é um "divisor de águas" na vida dos sujeitos atingidos por tal processo. Mesmo tendo surgido no penúltimo período do curso um período, gerando uma série de transtornos aos alunos da turma inicial - como perspectivas profissionais e acadêmicas, concursos públicos etc. - os alunos que participaram de nossa pesquisa de campo reconheceram o valor social do curso em suas vidas e o quanto o mesmo impactou positivamente em suas histórias.

Contudo, mesmo reconhecendo o impacto social do curso em questão, os alunos não deixam de pontuar o contexto de precariedades e de carências estruturais sob as quais o curso de Pedagogia começou. Separamos, aqui, alguns trechos de três entrevistas que fazem referência a dificuldades encontradas durante o curso de Pedagogia:

As principais dificuldades, no início, não tinha transporte direito pra cá, pra o Campus, porque é distante e essa parte da cidade não era muito movimentada à noite, então não tinha transporte no início. A biblioteca do campus começou a funcionar acho que quando eu estava no quarto ou no quinto período foi que começou a funcionar a biblioteca, porque ficava fechada. E a xerox que também não funcionava no início, começou a funcionar a partir acredito que do terceiro período, ou no quarto foi que a xerox começou a funcionar. A coordenação também não funcionava à noite, não tinha ninguém que ficasse aqui na secretaria aqui à noite, só ficava apenas com os alunos e a coordenadora do curso, que vinha porque ela ficava preocupada com a gente. Mas na secretaria não ficava ninguém. Aí a partir do quarto, quinto semestre, quinto período foi que começou a funcionar a secretaria, aí funciona até nove, às vezes nove e trinta, a biblioteca começou também a funcionar todas as noites (Aluno 1, entrevistado 5).

A principal dificuldade: transporte (...). Também questão de biblioteca a gente não tinha apoio, questão de lanche, assim, foram coisas que (...) é, afetaram bastante. E que a gente conseguiu, assim, no meiozinho do curso pra o final. Porque assim, a biblioteca era fechada, o NTI era fechado, a coordenação (...). Então era muito complicado. Até que do meio pra o final, começou mais essa questão de secretaria (Aluno 2, entrevistado 6).

No início era a assistência, não dava assistência nenhuma, não tinha biblioteca, cantina era fraca, a xerox não tinha, não tinha. Mas a partir do momento que foi entrando mais cursos, aí foi melhorando. E até agora só melhorias mesmo. É (...) a não ser isso, pra mim não, que o transporte vem me deixar aqui na porta e espera pra eu voltar, mas o pessoal daqui reclama muito do transporte. Não tem uma linha certa que passe em horários alternados, com frequência (Aluno 4, entrevistado 8).

O curso de Pedagogia da UFAL-Campus Arapiraca inicia suas atividades sem estrutura mínima adequada, a começar pela questão da organização dos períodos. A UFAL já tinha no Campus A.C. Simões um curso noturno de Pedagogia, organizado, por exigência do MEC, em nove períodos. Cria-se o curso do Campus Arapiraca também noturno, porém com oito períodos. Em 2014, com quatro anos de existência da primeira turma, anuncia-se através do PPC (2014) que deveria ser acrescido mais um período para o curso, incluindo a primeira turma que a essa altura já estava próximo do fim, gerando uma série de transtornos como elencado há pouco. Esses transtornos poderiam ter sido evitados se a UFAL tivesse utilizado seu próprio modelo de curso de Pedagogia noturno existente no Campus A. C. Simões.

Percebemos aqui um problema de identidade institucional associado à questão da precarização. A mesma universidade apresenta modelos de graduação díspares a depender de onde a mesma esteja 
situada: capital ou interior. E o motivo desta disparidade não é necessidade regional, como afirmado oficialmente em seus documentos, pois se o fosse o Agreste não ia ter o mesmo modelo, ipse litere, do Sertão, mas sim a racionalidade de recursos necessários ao projeto de interiorização da referida universidade.

Por conta dessa racionalidade de recursos físicos e humanos, inicia-se o curso sem técnicos para dar suporte aos alunos no decorrer das aulas, sem uma presença fixa da coordenação, sem secretaria, sem possibilidades de uso da biblioteca, sem um local no interior do Campus para fotocopiar textos, sem cantina para lanches. Observe-se que os alunos não colocaram nem a questão do Restaurante Universitário. Não se tinha nem onde comprar um lanche. O Aluno 6 resume bem a situação da primeira turma: "[...] enfrentamos várias dificuldades na estrutura física e curricular" (Aluno 6, questionário 2).

A precarização presente no curso de Pedagogia interiorizado pela UFAL dialoga intensamente com os princípios da Reforma Capanema, reeditados na ditadura militar por Meira Mattos, de se ofertar uma educação mitigada para os pobres. Observando a origem socioeducacional dos graduandos da primeira turma de Pedagogia, considerando a categoria administrativa da instituição na qual cursaram o ensino médio, percebemos que, dos 31(trinta e um) alunos, apenas 7 (sete) estudaram em escolas ligadas à rede privada.

Majoritariamente, os alunos atendidos por esse curso precarizado são advindos de escolas públicas. Contudo, esse dado não pode ser interpretado de forma unívoca, pois se, por um lado, dialoga com uma forma classista de expandir a educação; por outro, quebra-se uma paradigma em relação ao acesso à educação superior por parte de alunos pertencentes à rede pública de ensino de Alagoas que não teriam possibilidades de deslocamento para Maceió ou mesmo de pagar uma IES privada:

É de grande importância, principalmente porque aqui em Arapiraca a gente só tinha a opção da UNEAL. E na época era muito concorrido, e tal, e quando veio pra cá nos auxiliou bastante, justamente por essa questão de não ter outra universidade além da UNEAL, e a concorrência ser grande, e a gente não ter condições de pagar uma particular. Então é muito importante, foi muito importante a vinda pra Arapiraca (Aluno 3, entrevistado 7).

Mesmo com suas precariedades, o curso de Pedagogia, segundo os entrevistados, vem cumprindo um papel social importante para expansão e democratização da educação pública e gratuita. Nesse sentido, o curso ampliou as oportunidades para egressos do ensino médio que tinham interesse na Pedagogia como formação de nível superior, mas não tinham condições de pagar pelo mesmo. Contudo, sabemos que não é suficiente ampliar o acesso, é necessário também dar as condições, por meio das políticas internas de assistência estudantil, para a permanência do aluno na universidade.

É interessante observar também que de uma amostra de 31 (trinta e um alunos), apenas 5 (cinco) não estiveram envolvidos em atividades extracurriculares. Contudo, dos vinte e seis respondentes envolvidos em atividades extracurriculares, somente dois participaram de atividades voltadas especificamente à pesquisa, por meio do Programa Institucional de Bolsas de Iniciação Científica (PIBIC). Os vinte e quatro restantes participaram de atividades voltadas ao ensino: Monitoria e Programa Institucional de Bolsas de Iniciação à Docência (PIBID). Embora tais atividades possam estar relacionadas a atividades de pesquisa, o foco é o ensino, seja na graduação, no caso da monitoria, seja na educação básica, como é o caso do PIBID. Isso pode indicar que o espaço para a pesquisa no curso de Pedagogia da UFAL - Campus Arapiraca não é uma prioridade. Pode-se afirmar que o Campus Arapiraca é fruto de um processo de expansão precarizada das universidades brasileiras e materializa, em sua organização curricular, um modelo econômico de universidade que, por conseqüência, privilegia o ensino em detrimento da pesquisa e da extensão, desarticulando o tripé que sustenta a universidade.

Essa racionalidade materializa-se na própria estrutura física do Campus que é pensada já nesse viés da racionalidade absoluta de recursos humanos, ocasionando a sobrecarga docente e o privilégio do ensino em detrimento da pesquisa e da extensão: 
Então essa economia também passa por essa organização de Troncos. Tem um batalhão de frente ali, sempre. Depois o outro, depois o outro. São turmas grandes, as salas são grandes (...). A própria estrutura. Algumas salas fizemos duas. [...] Agora, a entrada, principalmente do tronco inicial, é pesado. É pesado (...). Pra gente já alivia um pouquinho. Mas, tinha professores com 120 horas, imagine o que é isso numa disciplina como Sociedade e Conhecimento, 120 horas com turmas superlotadas (Professor 2, entrevistado 9).

À medida que fomos nos aproximando da experiência do curso de Pedagogia, foi ficando claro que, de fato, a organização curricular em Troncos de Conhecimento é a materialização da lógica da otimização de recursos humanos e físicos postulada pelo REUNI. Os Troncos Inicial e Intermediário são, como caracterizou o Professor 2, exércitos de frente que com o mínimo possível de professores e salas dão conta de uma grande demanda inicial do Campus Arapiraca, trazendo dificuldades não somente aos alunos, mas também aos professores, ocasionando sérios problemas à formação docente:

No Tronco Inicial, há normalmente um número excessivo de alunos em sala de aula, dificultando o processo de ensino-aprendizagem. Há, no geral, um isolamento maior entre as disciplinas e uma vinculação na formação centrado na profissão pragmática e pouco desenvolvimento teórico na formação (Professor 14, questionário 12).

Essa reflexão dialoga com o pensamento do Professor 1 que percebe, nessa estrutura curricular flexibilizada, uma tendência de priorizar a arte do fazer, em detrimento da reflexão teórica dos conteúdos fundamentais inerentes a cada área de formação. Segundo o Professor 3,' que está no Campus Arapiraca desde o início do Curso de Pedagogia, essa organização foi válida na experiência inicial do Campus, mas, no momento atual, não faz mais sentido e não se sustenta:

Essa estrutura de Troncos não é positiva. Isso por que, em minha opinião, fragmenta o saber pedagógico, concentrando-o, de forma geral no que concerne às licenciaturas, em um único período - o intermediário - o que tem tornado a interação com os saberes "profissionais" do Tronco Profissionalizante pouco efetiva e pouco compreendida. Esses são só alguns elementos que, acredito, interferem negativamente na formação dos licenciados (Professor 3, questionário 1).

Nessa mesma perspectiva, argumenta o Professor 4, mostrando que tal organização materializa uma prática funesta à formação docente:

[... ] a proposta pedagógica, do ponto de vista filosófico, é muito boa, mas sua execução é condenável. Defendo a ideia que as disciplinas do Tronco Inicial fossem distribuídas no longo do curso e as do Tronco Intermediário também, para não sobrecarregar os estudantes em atividades das disciplinas pedagógicas (Professor 4, questionário 2).

$\mathrm{Na}$ perspectiva filosófica, tal projeto justifica-se por responder às exigências pós-modernas do pensamento complexo, fronteiriço, transdisciplinar, dialogando com os teóricos da terceira via para mascarar a intencionalidade racional-econômica, proposta pelo capital internacional aos países da periferia do capital para expansão da educação superior a baixo preço, por meio da construção de uma conjuntura ideológica para defesa de um projeto inovador, racional, flexível e econômico em recursos humanos e materiais que na prática resulta em sérios problemas, especialmente para os professores e alunos envolvidos nos cursos.

O projeto pedagógico do Campus Arapiraca, tendo o argumento da interdisciplinaridade como destaque, deixa na sombra um projeto econômico em termos de trabalho docente: "[...] há um mascaramento da necessidade de concurso para mais docentes, pois os professores dos Troncos Inicial e Intermediário atendem a vários Cursos" (Professor 10, questionário 8).

Nota-se aqui uma consequência direta do modelo curricular assumido para expandir a educação superior pública em Alagoas: a precarização do trabalho docente. Os professores dos Troncos Inicial e 
Intermediário são os exércitos de frente responsáveis por atender a grande demanda inicial do Campus. Nesse caso, a precarização se dá por excesso de alunos em sala, pelo trabalho docente focado tão somente no ensino e pela escassez de recursos físicos:

A estrutura tá sempre precária. Estrutura física, condição climática, calor. Tem dias ali no verão que os alunos não aguentam, não é só o professor. Eu já tive aluno de passar mal por causa do calor. Uma e meia quando a gente inicia, 2 horas, ou até quem vai até 11 e meia é insuportável. Então as condições de, de estruturas físicas, dentro da universidade, são muito precárias lá na UFAL. Fora a convivência que a gente fala, não seria social, mas a convivência de espaço, não tem Restaurante Universitário, não tem (...) (Professor 2, entrevistado 9).

Essa realidade precária da estrutura física faz parte do conjunto da obra do projeto pedagógico da UFAL para o interior de Alagoas. Projeto este, pautado nos ideias do REUNI, de melhor aproveitamento dos recursos humanos e físicos da universidade:

Do ponto de vista financeiro, o projeto de Arapiraca é muito mais racional, muito mais econômico. Então, as formas de expansão que a gente vê na universidade é exatamente essa, expandindo cada vez mais vagas à distância, porque são muito mais baratas que as vagas presenciais. Cada vez mais expandindo cursos, universidades ou campi que têm estrutura pedagógica mais (...) que eles chamam de moderna, né, mais nova, que na verdade correspondem a uma estruturação pedagógica mais racional do ponto de vista administrativo e econômico. É isso que acontece com os campi daqui do interior de Alagoas (...). Eu não duvido que quem pensou isso não acredite de verdade que é uma forma mais pedagógica, ou, como se aponta, propedêutica e tal. Mas efetivamente, isso se mostra mais racional do ponto de vista administrativo. Pode ser que a lógica ou a intencionalidade não estava presente quando isso foi pensado, mas é isso que ela materializa (....) (Professor 1, entrevistado 4).

Nessa perspectiva da racionalidade administrativa dos recursos humanos e físicos, surge uma fragilidade desse formato curricular, pautado na via econômica da racionalidade, a precariedade pedagógica:

Você tem uma situação na qual o tronco inicial que é igual pra todos os cursos independente de área [...]. Depois você tem um segundo tronco, no segundo semestre, que ele chama de tronco intermediário que é igual por área. Então no caso das licenciaturas, por exemplo, todas as licenciaturas, o cara pode tá fazendo Letras ou pode tá fazendo Matemática, ou Educação Física. O segundo semestre é igual pra todos. E só no terceiro período, quer dizer, quando o sujeito já tá no segundo ano de universidade, é que ele vai ter contato com as disciplinas do seu curso. Então você tem evidentemente aí uma formação que do ponto de vista da qualificação, do ponto de vista da qualidade já coloca uma série de problemas. Como é que você entra num curso e vai começar a ver disciplinas do seu curso só a partir do segundo ano? Então já coloca um problema. Você tem aí já um processo de estruturação pedagógica que evidentemente é mais precário do ponto de vista pedagógico (Professor 1, entrevistado 4).

No que diz respeito à estrutura curricular em específico do curso de Pedagogia, todos os entrevistados apontaram para o dado de que não foi uma opção adotar a estrutura de troncos de conhecimento, mas sim uma condicio sine qua non. A única possibilidade para a criação de um curso de pedagogia no Campus Arapiraca era de um curso orientado pela lógica da otimização. Nesse sentido, as principais articulações realizadas pela equipe responsável foi com o curso de Pedagogia do Campus Sertão, cuja estrutura curricular já era flexibilizada em troncos de conhecimento. Assim, no Campus Arapiraca foi feita uma adequação do projeto político pedagógico do curso de pedagogia do Campus do Sertão: 
Quando o projeto chega da Pedagogia, nós recebemos esse projeto pronto. Nós não iniciamos esse processo [...]. Mas no fundo, nós fizemos uma revisão. Eu diria assim, uma reorganização do projeto do curso de Pedagogia de Delmiro. É aí que consta os nossos nomes como Equipe de Adequação. Mas sem autonomia de mexer na estrutura do próprio projeto maior do campus, que você conhece a partir do tronco inicial, intermediário e profissionalizante (Professor 2, entrevistado 9).

Basicamente o que a gente fez foi pegar a grade curricular que já existia do campus Sertão, do curso de Pedagogia, a gente pegou o Projeto Político Pedagógico que já existia do campus Delmiro Gouveia, só que lá é diurno, né? Então a gente pegou aquele projeto e alterou o essencial que gente podia alterar pra atender nossas necedades, necessidades de Arapiraca. E tentamos corrigir no que a gente julgou que seria necessário, mas havia alguns limites, quer dizer, a gente sabia de antemão, e aí, e aí é isso uma das formas que esse rebaixamento se aplica, porque alguns limites são colocados e... E as mediações pelas quais esses limites se dão, é das formas mais sutis ou mais imediatizadas que a gente possa julgar. O que acontece? Pra que o curso fosse aprovado, ele teria que ter algumas características, do contrário, O MEC não aprovaria (Professor 1, entrevistado 4).

Não houve discussões ou escolhas em relação ao formato curricular do curso a ser criado. Ou surgia no formato flexibilizado em troncos de conhecimento ou não surgia. Se não fosse nesse modelo, não seria aprovado pelo MEC, pois estaria fora do espírito racional e supostamente inovador de sua unidade. Nesse sentido, a UFAL ignora que já tinha um curso noturno de Pedagogia em Maceió, trazendo uma série de complicações para o novo curso que teve início em Arapiraca. Um delas foi a duração do curso: os alunos se matricularam em um curso de oito períodos que, por exigência do MEC, passou a ter nove já depois de metade do curso realizado, gerando transtornos aos alunos, como apresentado no item anterior.

A articulação crucial, quase que obrigatória, para criação do curso de Pedagogia da UFAL - Campus Arapiraca foi com o curso de Pedagogia do Campus Sertão. Na verdade, o projeto Pedagógico do Curso de Pedagogia do Campus Arapiraca é o mesmo do Curso de Pedagogia do Campus Delmiro Gouveia, porém, adequado à realidade de Arapiraca. Dessa forma, a equipe de professores responsáveis pela elaboração do PPP é a mesma no PPP dos dois Campi, sendo acrescentada, no caso do Campus Arapiraca, uma equipe de adequação formada por três professores que faziam parte do Núcleo Pedagógico de Arapiraca. Desses três professores, dois fizeram parte de nossa pesquisa de campo, caracterizados como Professor 1 e Professor 2.

Mesmo tentando-se algumas mudanças para organização do curso de Pedagogia, havia limites estruturais para um melhor direcionamento do Curso. Nesse sentido, o limite central posto à construção do projeto pedagógico do curso foi justamente o formato curricular do mesmo que tinha que ser idêntico ao formato curricular dos outros cursos do Campus. Por isso, não houve uma construção do projeto, mas sim uma adequação do projeto do curso de Delmiro para o de Arapiraca. Para os professores que participaram da equipe responsável pela criação do curso de Pedagogia no Campus Arapiraca, o formato curricular exigido é a materialização de uma expansão da educação superior menos qualificada, caracterizando um rebaixamento geral da educação que se intensifica na Pedagogia:

Então, se há um rebaixamento de modo geral da educação, esse rebaixamento se passa de forma privilegiada exatamente pela Pedagogia, que é o curso, por excelência, da educação. Como o rebaixamento atinge toda a educação, ele se evidencia maior naquela formação que vai pensar justamente a educação. Então, eu diria que no caso de Pedagogia o rebaixamento é mais grave ainda do que em qualquer outro curso, porque é ela quem vai pensar as políticas, ela quem vai pensar a estruturação pedagógica, ela quem vai pensar os pedagogismos etc. $O$ que a gente tentou na estruturação lá do projeto, que eu acho que não foi feliz totalmente por conta dos limites já impostos, foi tentar dar um caráter mais de 
fundamento ao curso de Pedagogia. Mas de um modo geral, esse rebaixamento da educação evidentemente atinge muito mais a Pedagogia do que qualquer outro curso (Professor 1, entrevistado 4).

Todavia, mesmo reconhecendo os limites estruturais do processo de expansão da UFAL, há um grande consenso entre os docentes, que participaram de nossa pesquisa de campo, no que diz respeito à forma de os mesmos avaliarem a presença da UFAL em Arapiraca e o curso de Pedagogia em específico:

Inegavelmente, expandir educação é um processo enriquecedor do ponto de vista social. Nesse sentido, os aspectos positivos se sobressaem em relação aos aspectos negativos [...]. Essa expansão ao interior traz aspectos extremamente positivos. A gente possibilita que aquele indivíduo do Agreste, do Sertão, de uma periferia do estado que já é periférico, de um país periférico do mundo, etc., tenha acesso a um horizonte, a uma leitura de mundo. Possibilita que ele acesse um grau de riqueza social maior do que ele poderia ter se a universidade não tivesse chegado ali. A maioria dos nossos alunos são alunos que não iriam pra universidade. Eu tenho alunos e é, a imensa maioria, que nunca vieram pra Maceió, por exemplo. Não conhecem a capital. A maioria, mas a imensa maioria mesmo dos alunos, são alunos de escola pública. Um ou outro que é de escola privada. Você tem uma realidade que, de fato, a universidade está lá e tá a serviço exatamente daqueles sujeitos oriundos da classe trabalhadora (Professor 1, entrevista 4).

Há inegavelmente um grande ganho para o aluno que visualiza na UFAL que chegou ao interior uma possibilidade de um mundo diferente. Mesmo que seja uma universidade precarizada, com limites estruturais, a universidade federal chegando ao interior de Alagoas realiza uma trajetória de ganhos imateriais e materiais para jovens, advindos da rede pública de ensino, que no Campus Arapiraca da UFAL visualizam novas possibilidades:

O curso foi muito importante, porque a partir do momento que eu saí do Ensino Médio, da Educação Básica, eu tinha uma visão de mundo que é (...) Acompanhando com a dos jovens de hoje, por não ter um estímulo na escola básica, você faz aquela mesmice, você sai dali e quer trabalhar naquela, naquela zona. Quando você alcança a universidade e começa a ter novos olhares, novos horizontes, você começa a abrir horizontes. Um leque que você nem imaginava alcançar (Aluno 4, entrevistado 8).

É interessante a forma que os alunos vão se percebendo dentro da universidade, pois tal dado ocasiona uma mudança regional de comportamentos. A chegada da UFAL ao agreste realizou uma grande mudança de mentalidade nos estudantes de Arapiraca e de seu entorno, surgindo novos mundos possíveis:

As meninas começaram a perceber que o casamento não era o único caminho pra elas. Até eu dizia assim: meninos, cuidado, que as meninas aqui querem casar. E hoje eles me encontram, professora, olha, ainda não casei, ou professora, casei. Não estava criticando elas diretamente, mas o contexto do interior demandava isso, que a perspectiva que elas tinham era de um casamento. De terminar o Ensino Médio e casar. E eu percebo que isso ampliou. Claro que elas continuam querendo casar como todo mundo, mas não sendo o único caminho. Eu tenho especialização, professora, vou fazer um mestrado, doutorado (...). E eu fico feliz que ampliou o universo também das mulheres no agreste alagoano. Hoje, o aluno chega na universidade sem grandes diferenças em relação a Maceió. Eu fiz uma prova agora e tem alunos que escrevem 4 páginas sobre aquele tema. Isso é importante. O perfil do aluno hoje é outro, que entra na universidade, né? Sim, então você percebe que você tem alunos ali já doutores no leste europeu, com 
26 anos. Da Física, da Educação Física na Bahia. Pedagogia não, que não teve tempo ainda, mas da Biologia (Professor 2, entrevista 9).

Essa mudança de mentalidade é, em alguma medida, reflexo da presença da universidade federal no interior de Alagoas, impactos de sua presença na região agrestina, fazendo com que seus jovens percebam que há uma pluralidade de caminhos possíveis, de novos mundos a serem desbravados. A universidade que chega ao agreste, de fato, é precária, mas consegue impactar positivamente no interior do estado de Alagoas, estado esse marcado pelo retrocesso econômico e social da cultura da cana-deaçúcar.

\section{REFERÊNCIAS}

ARRUDA, Ana Lucia Borba de. Expansão da educação superior: uma análise do programa de Apoio a Planos de Reestruturação e Expansão das Universidades federais (REUNI) na Universidade Federal de Pernambuco. 2011. 228f. Tese (Doutorado em Educação) - Universidade Federal de Pernambuco, Recife, 2011.

BRASIL. Decreto $n^{0}$ 6.096, de 24 de abril de 2007a. Institui o Programa de Apoio a Planos de Reestruturação e Expansão das Universidades Federais - Reuni. Brasília, 24 abr. 2007. Disponível em:

http://www.planalto.gov.br/ccivil_03/_at02007-2010/2007/decreto/d6096.htm. Acesso em: 10 de outubro de 2012.

. Reuni. Reestruturação e Expansão das Universidades Federais: Diretrizes Gerais. Brasília, Agosto de 2007b. Disponível em: http://portal.mec.gov.br/sesu/arquivos/pdf/diretrizesreuni.pdf. Acesso: 20 ago. 2014.

CAVALCANTE, Maria do Socorro Aguiar; SOBRINHO, Helson Flávio da Silva. Das questões fundantes do discurso à instância da política: uma síntese de múltiplas determinações. Leitura: Revista do programa de pós-graduação em Letras da UFAL, Maceió, n. 50, p. 83-108, 2012.

BARDIN, Laurence. Análise de Conteúdo. 4. Ed. Lisboa: Edições 70, 2009.

WESKA, Adriana Rigon. O programa REUNI na Universidade Federal de Juiz de Fora. 2012. 92f. Dissertação (Mestrado em Gestão e Avaliação da Educação Pública) - Universidade Federal de Juiz de Fora, Juiz de Fora, 2012.

FONSECA, Davi. O REUNI e a expansão precarizada da Universidade brasileira no contexto da crise estrutural do Capital. 2013.144f. Dissertação (Mestrado em Educação) - Universidade Federal de Alagoas, Maceió, 2013.

OLIVEIRA, Eliana de. Análise de conteúdo e pesquisa na área da educação. Revista Diálogo Educacional: Revista do PPGE da PUCPR. Curitiba, v. 4, n.9, p.11-27, maio/ago. 2003.

PAULA, Cristina Maria de. Neoliberalismo e reestruturação da Educação Superior no Brasil: o REUNI como estratégia do governo Lula e da burguesia brasileira para subordinar a Universidade à lógica do atual estágio de acumulação do capital. 2009. 246f. Dissertação (Mestrado em Educação) - Universidade Federal Fluminense, Niterói, 2009.

SANTOS, Lavoisier Almeida dos. Reforma universitária e flexibilização curricular: uma análise do REUNI no agreste alagoano. 2016. 148f. Dissertação (Mestrado em Educação) - Universidade Federal de Alagoas, Maceió, 2016.

SGUISSARDI, Valdemar. Modelo de expansão da educação superior no Brasil: predomínio privado/mercantil e desafios para a regulação e a formação universitária. Educação \& Sociedade, Campinas, vol. 29, n. 105, p. 991-1022, 2008.

SILVA, Cristiane Rocha. et al. O uso da análise de conteúdo como uma ferramenta para a pesquisa qualitativa: descrição e aplicação do método. Organizações Rurais e Agroindustriais: Revista de Administração da UFLA, Lavras, vol. 7, n. 1, p. 70-81, 2005.

SILVA JUNIOR, João dos Reis; SGUISSARDI, Valdemar. Universidade Pública brasileira no Século XXI: educação superior orientada para o mercado e intensificação do trabalho docente. Espacios en Blanco. 
Revista de Educación, Universidad Nacional del Centro de la Provincia de Buen”os: Aires Buenos Aires, Argentina, n. 23, junio, p. 119-156, 2013.

UNIVERSIDADE FEDERAL DE ALAGOAS. Plano de Desenvolvimento institucional (2000-2003). Maceió, 2000.

2005.

. Projeto de Interiorização da Universidade Federal de Alagoas: uma expansão necessária. Maceió,

. Plano de Desenvolvimento institucional (2006-2008). Maceió, 2006.

. Plano de Desenvolvimento institucional (2008-2012). Maceió, 2008.

. Plano de Desenvolvimento institucional (2013-2017). Maceió, 2013.

. PROJETO REUNI DA UNIVERSIDADE FEDERAL DE ALAGOAS (2008-2012). Maceió, 2007.

. PROJETO PEDAGÓGICO DO CURSO DE PEDAGOGIA LICENCIATURA. Arapiraca, 2014. Disponível em http://www.ufal.edu.br/arapiraca/graduacao/pedagogia/projeto-pedagogico/ppc-pedagogia/view. Acesso em 15 mar. 2015.

. PROJETO POLÍTICO PEDAGÓGICO DO CURSO DE PEDAGOGIA LICENCIATURA. Arapiraca, 2010.

Disponível em http://www.ufal.edu.br/arquivos/prograd/cursos/campus-arapiraca/Pedagogia\%20-

\%20UFAL\%20Arapiraca.pdf. Acesso em: 10 jan. 2015.

WESKA, Adriana Rigon. O programa REUNI na Universidade Federal de Juiz de Fora. 2012. $92 \mathrm{f}$. Dissertação (Mestrado em Gestão e Avaliação da Educação Pública) - Universidade Federal de Juiz de Fora, Juiz de Fora, 2012. 